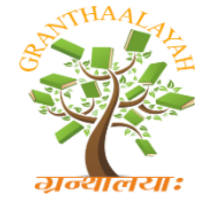

INTERNATIONAL JOURNAL OF RESEARCH GRANTHAALAYAH A knowledge Repository

RASM - 17

\title{
AN OVERVIEW OF DROUGHT ANALYSIS: ASSESSING DROUGHT SEVERITY BASED ON FLUCTUATION IN RAINFALL TREND BY STANDARD PRECIPITATION INDEX FOR SHIVAMOGGA DISTRICT
}

\author{
Kunal Kothari ${ }^{* 1}$, Bharath A.L ${ }^{2}$, Vishal Gadgihalli ${ }^{1}$, Aiman Hilal ${ }^{1}$ \\ ${ }^{* 1}$ UG Student, Department of Civil Engineering, Jain University, Bangalore, India \\ ${ }^{2}$ Assistant Professor, Department of Civil Engineering, Jain University, Bangalore, India
}

DOI: https://doi.org/10.29121/granthaalayah.v5.i4RASM.2017.3364

\begin{abstract}
The Standard precipitation index expresses the actual rainfall as a standardized departure with respect to rainfall probability distribution function and hence the index has gained importance in recent years as a potential job indicator permitting comparison across space and time. The computation of SPI requires long term data on precipitation.

Droughts are hydro metrological events affecting vast regions and causing significant structural and non-structural damages. Drought predictions may prevent these type of adverse consequences to a significant extant.

This work regarding the drought analysis by assessing the drought severity based on fluctuation in rainfall trend by standard precipitation index for Shivamogga district by 30years rainfall data from rain gauge reading of different station in different Taluk of Shivamogga district.

Keywords: Shivamogga District; Standard Precipitation Index; Drought Severity Analysis; Rainfall Data.

Cite This Article: Kunal Kothari, Bharath A.L, Vishal Gadgihalli, and Aiman Hilal. (2017). "AN OVERVIEW OF DROUGHT ANALYSIS: ASSESSING DROUGHT SEVERITY BASED ON FLUCTUATION IN RAINFALL TREND BY STANDARD PRECIPITATION INDEX FOR SHIVAMOGGA DISTRICT." International Journal of Research - Granthaalayah, 5(4) RASM, 17-26. https://doi.org/10.29121/granthaalayah.v5.i4RASM.2017.3364.
\end{abstract}

\section{Introduction}

Rainfall deficit for a location over certain period of time may lead to conditions of drought, draught affects the sustainability, water resources, economic status, agriculture and socioeconomic activities. As the rainfall of the regions varies, the intensity of draught varies correspondingly .So World Meteorological Organization (WMO) recommends adopting the Standard Precipitation Index (SPI) to look after the severity of draught events. 
- Standard Precipitation Index shows the probability of rainfall occurrence compared with climatologically rainfall over a 30-60years for a particular location.

- The positive SPI indicates the intensity rainfall of certain location.

- The negative SPI indicates the drought of certain location.

- This SPI can be calculated by taking rainfall intensity of $1,3,6,9,12,24$ month's periodic distribution. SPI now days can be obtained easily due to technological improvement.

- The main advantage of SPI is we can compare the rainfall of different climatic zones in world.

- Variety of research institutions, Universities, and National Metrological, hydrological services across the world has become a part of drought monitoring and early warning efforts.

- Because the SPI is normalized, wetter and dried climates can be represented in same way. Thus, wet periods can also be monitored using the SPI. However, it must be stressed that the SPI is not suitable for climate change analysis because temperature is not an input parameter.

In simple terms SPI is normalized index representing the probability of occurrence of observed rainfall amount at certain geographical condition [1]. More over the understanding that a deficit of precipitation as different impacts on ground water, reservoirs storage, soil moisture, snowpack and stream flow let American scientist McKee, Doesken and Kleist to develop the standard precipitation index in 1993[2].In addition, it is just as effective in analyzing wet periods/ cycles as it is in analyzing dry periods/cycles. Ideally, one needs at least 20-30 years of monthly values, with 50-60 years being optimal and preferred [3].

\section{Advantages}

- It is spastically consistent: It allows for comparison between locations of different climates.

- Its probabilitistic nature gives it historical context, which is well suited for decisionmaking.

- Fewer complexes to calculate than the PSID [4].

\section{Materials and Methods}

In this study, the daily rainfall data of 23 meteorological stations over a period of 30 years, which are well distributed in the Shivamogga district area, were used for draught analysis. The identification and assessment of drought severity were done using the SPI. Precipitation reading was compiled by using SPI designed by McKee and his colleagues at Colorado state university to quantify the precipitation data at a precision data at a location for specified time period. A gamma probability density function is fitted to the precipitation data and the cumulative distribution of precipitation is determined. An equiprobability transformation is then from the cumulative distribution to standard normal distribution with a mean off zero and variance of one. This transformed probability is SPI value, the intensities resulting from the SPI classified by the table below. Drought severity/ magnitude are calculated as the cumulative deficiency of precipitation below the threshold level and drought intensity is obtained by drought severity/ magnitude by drought duration [5]. 
[Kothari et. al., Vol.5 (Iss.4: RASM), April, 2017]

ISSN- 2350-0530(O), ISSN- 2394-3629(P)

ICV (Index Copernicus Value) 2015: 71.21

321 (CosmosImpactFactor), 2.532 (I2OR)

Recent Advances in Sustainable Materials

InfoBase Index IBI Factor 3.86

Table 1. SPI values

\begin{tabular}{|c|c|}
\hline $2.0+$ & extremely wet \\
\hline 1.5 to 1.99 & very wet \\
\hline 1.0 to 1.49 & moderately wet \\
\hline-.99 to .99 & near normal \\
\hline-1.0 to -1.49 & moderately dry \\
\hline-1.5 to -1.99 & severely dry \\
\hline-2 and less & extremely dry \\
\hline
\end{tabular}

\section{Results and Discussions}

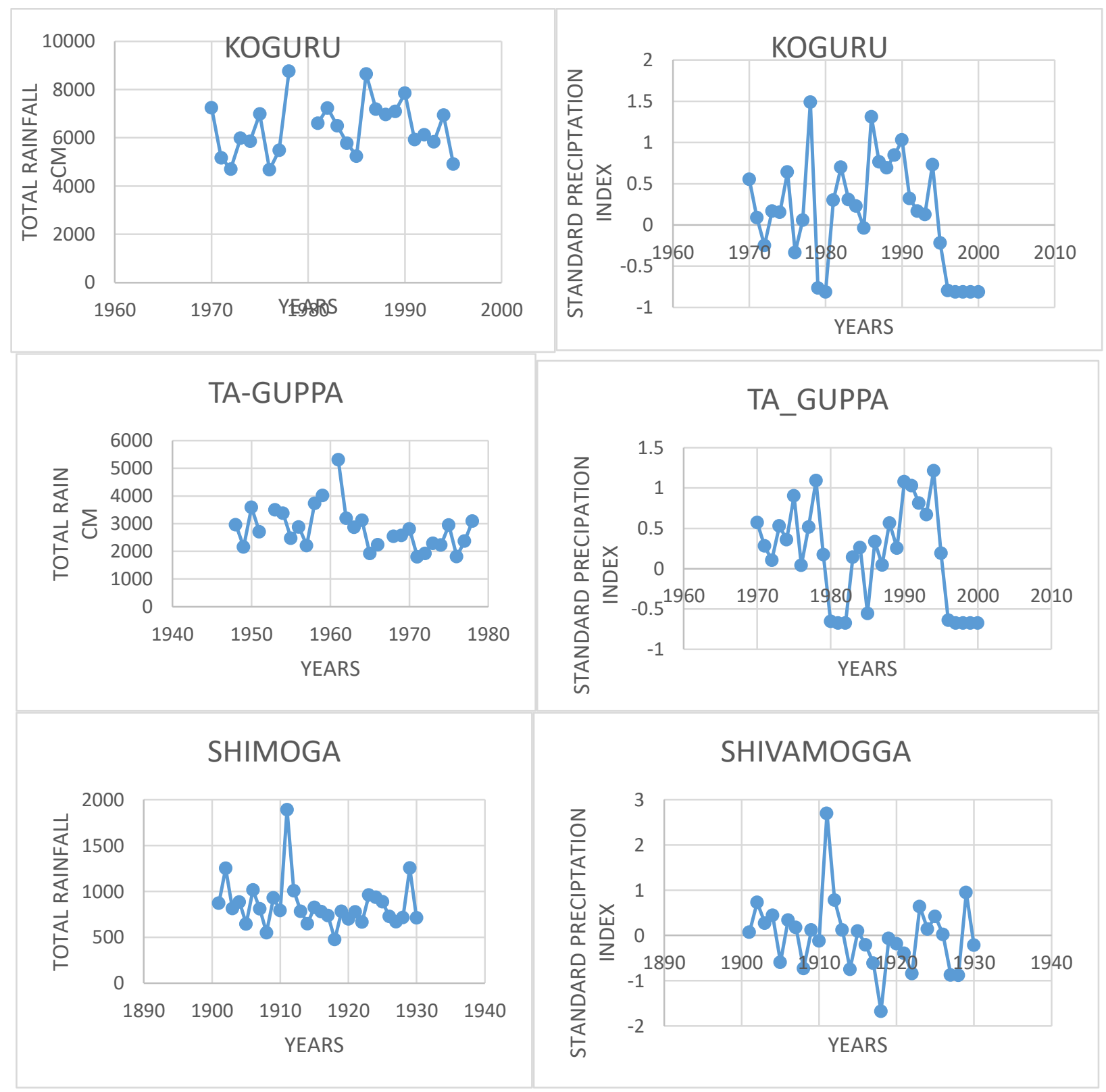


[Kothari et. al., Vol.5 (Iss.4: RASM), April, 2017]

ICV (Index Copernicus Value) 2015: 71.21

Recent Advances in Sustainable Materials
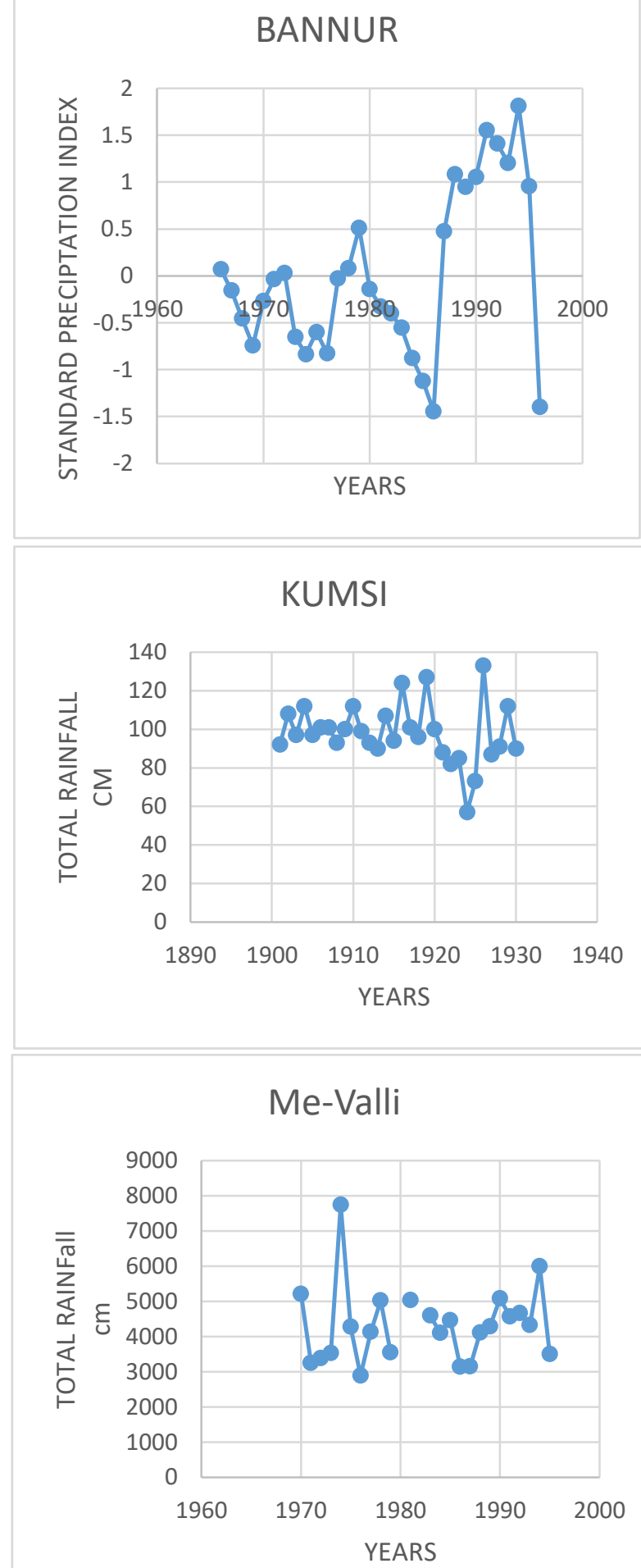

ISSN- 2350-0530(O), ISSN- 2394-3629(P)

IF: 4.321 (CosmosImpactFactor), 2.532 (I2OR)

InfoBase Index IBI Factor 3.86
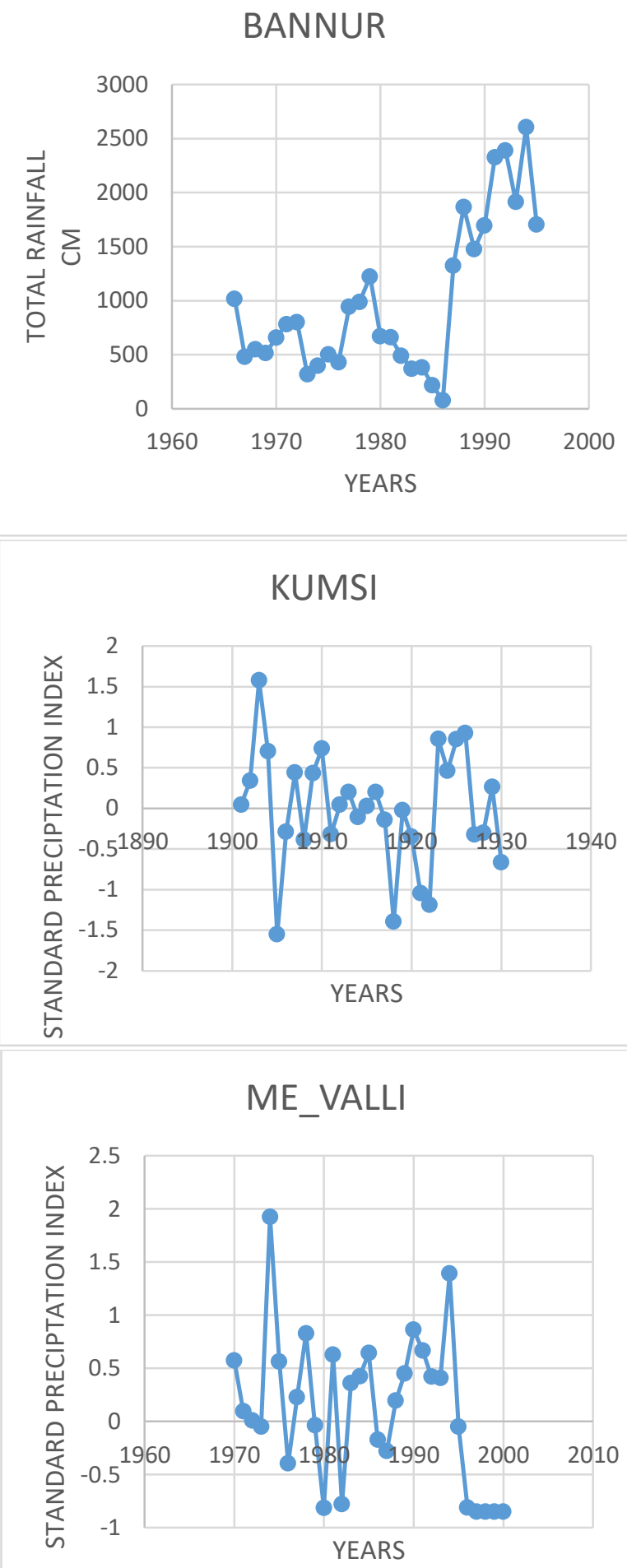
[Kothari et. al., Vol.5 (Iss.4: RASM), April, 2017]

ICV (Index Copernicus Value) 2015: 71.21

Recent Advances in Sustainable Materials
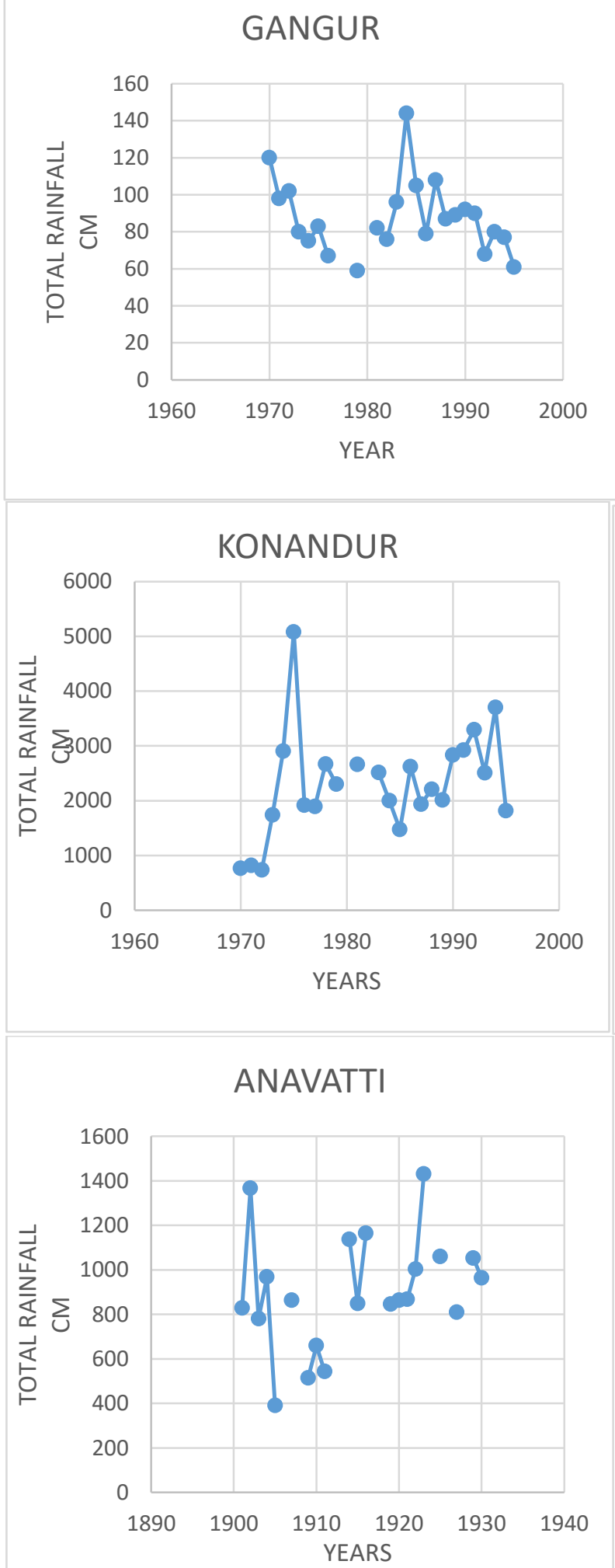

ISSN- 2350-0530(O), ISSN- 2394-3629(P)

IF: 4.321 (CosmosImpactFactor), 2.532 (I2OR)

InfoBase Index IBI Factor 3.86

GANGUR

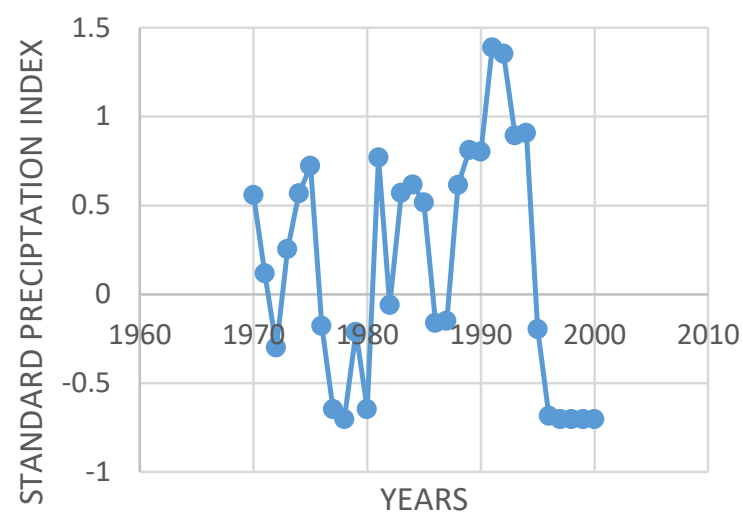

KONANPUR

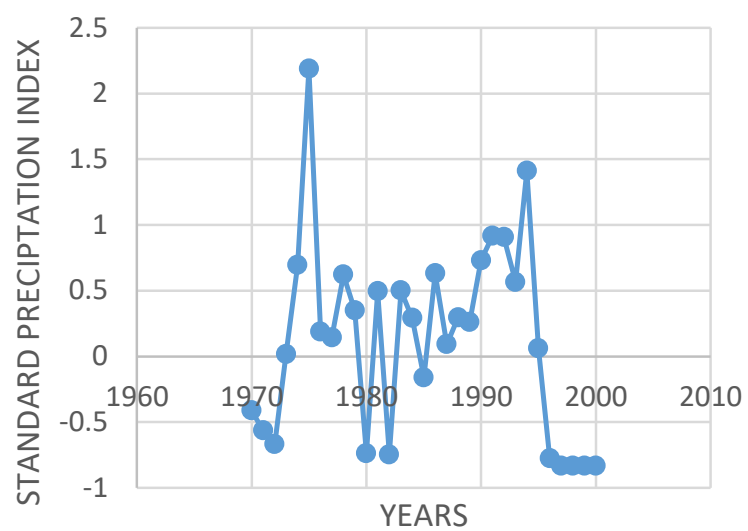

ANAVATTI

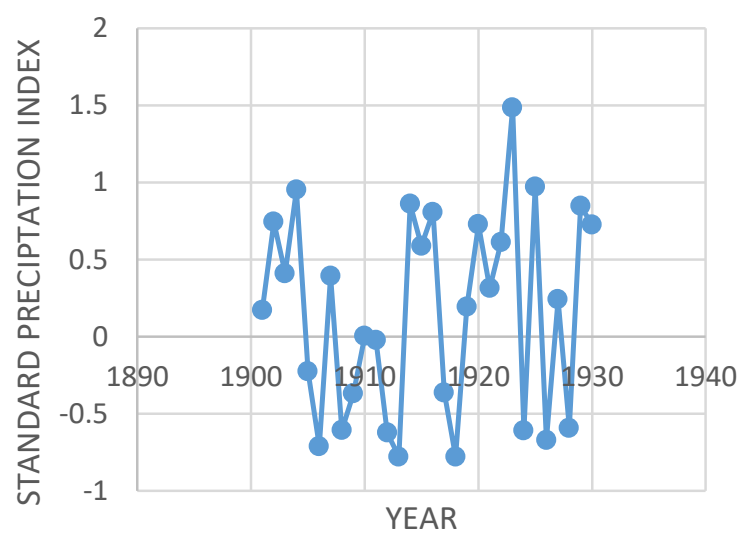


[Kothari et. al., Vol.5 (Iss.4: RASM), April, 2017]

ICV (Index Copernicus Value) 2015: 71.21

Recent Advances in Sustainable Materials

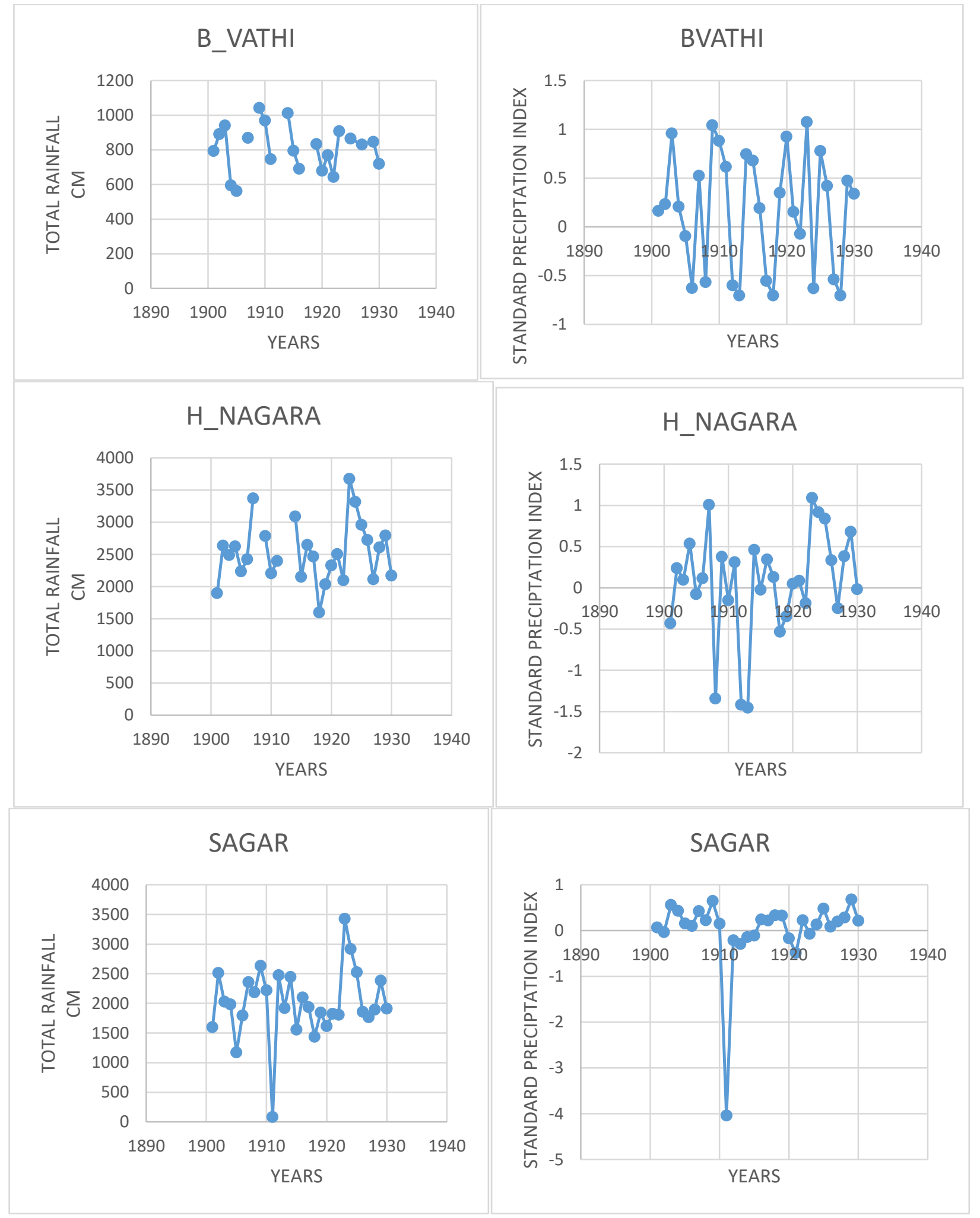


[Kothari et. al., Vol.5 (Iss.4: RASM), April, 2017]

ICV (Index Copernicus Value) 2015: 71.21

Recent Advances in Sustainable Materials

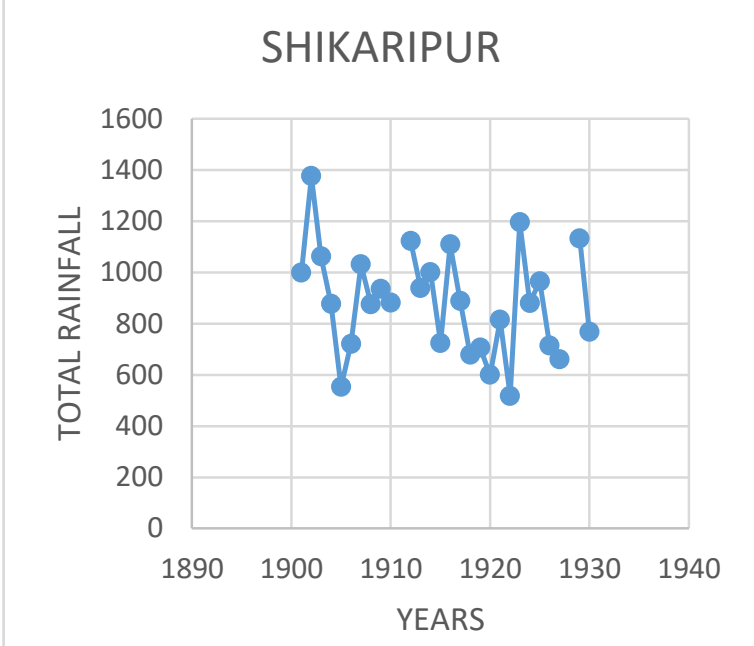

ISSN- 2350-0530(O), ISSN- 2394-3629(P)

IF: 4.321 (CosmosImpactFactor), 2.532 (I2OR)

InfoBase Index IBI Factor 3.86
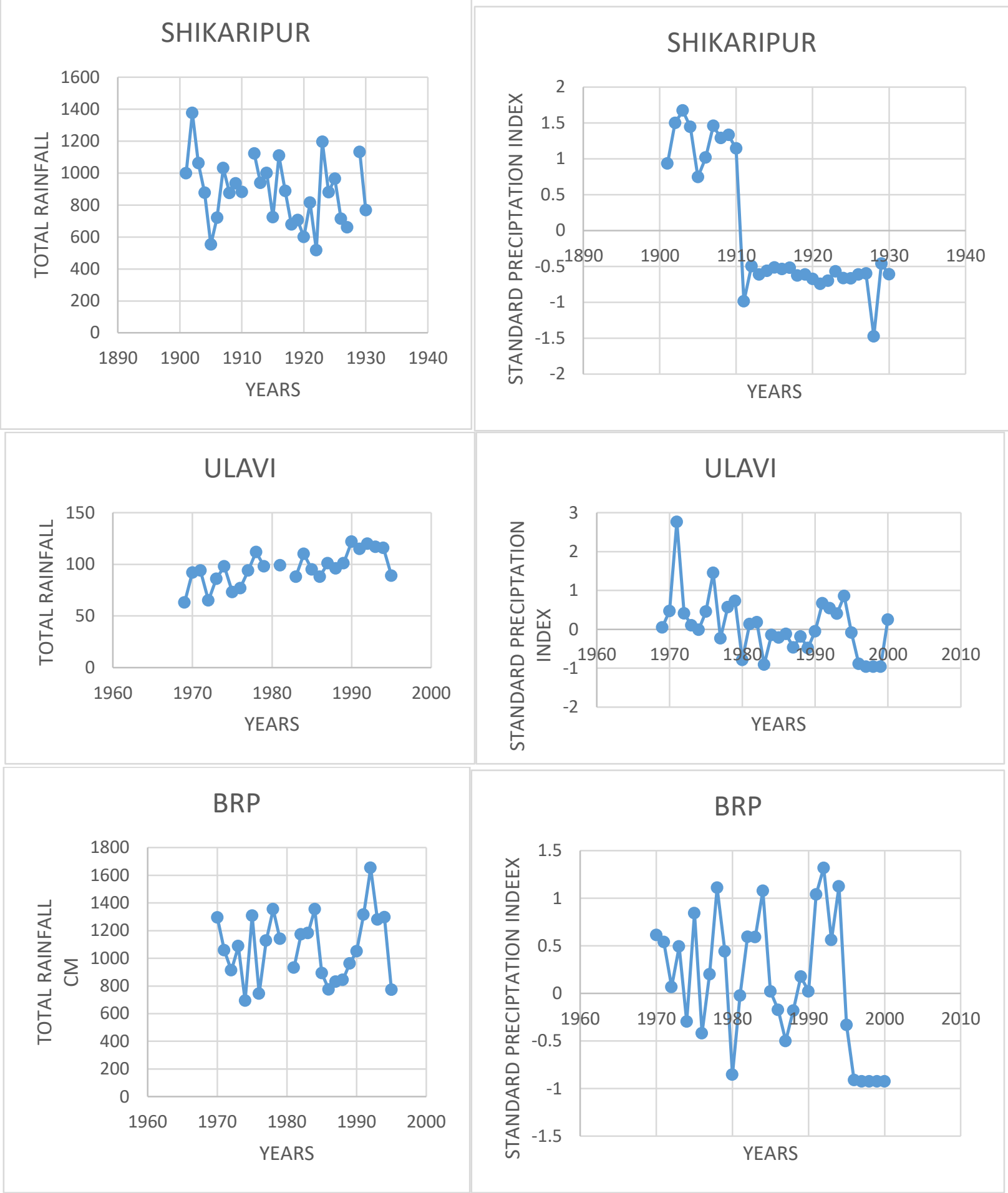
[Kothari et. al., Vol.5 (Iss.4: RASM), April, 2017]

ICV (Index Copernicus Value) 2015: 71.21

Recent Advances in Sustainable Materials

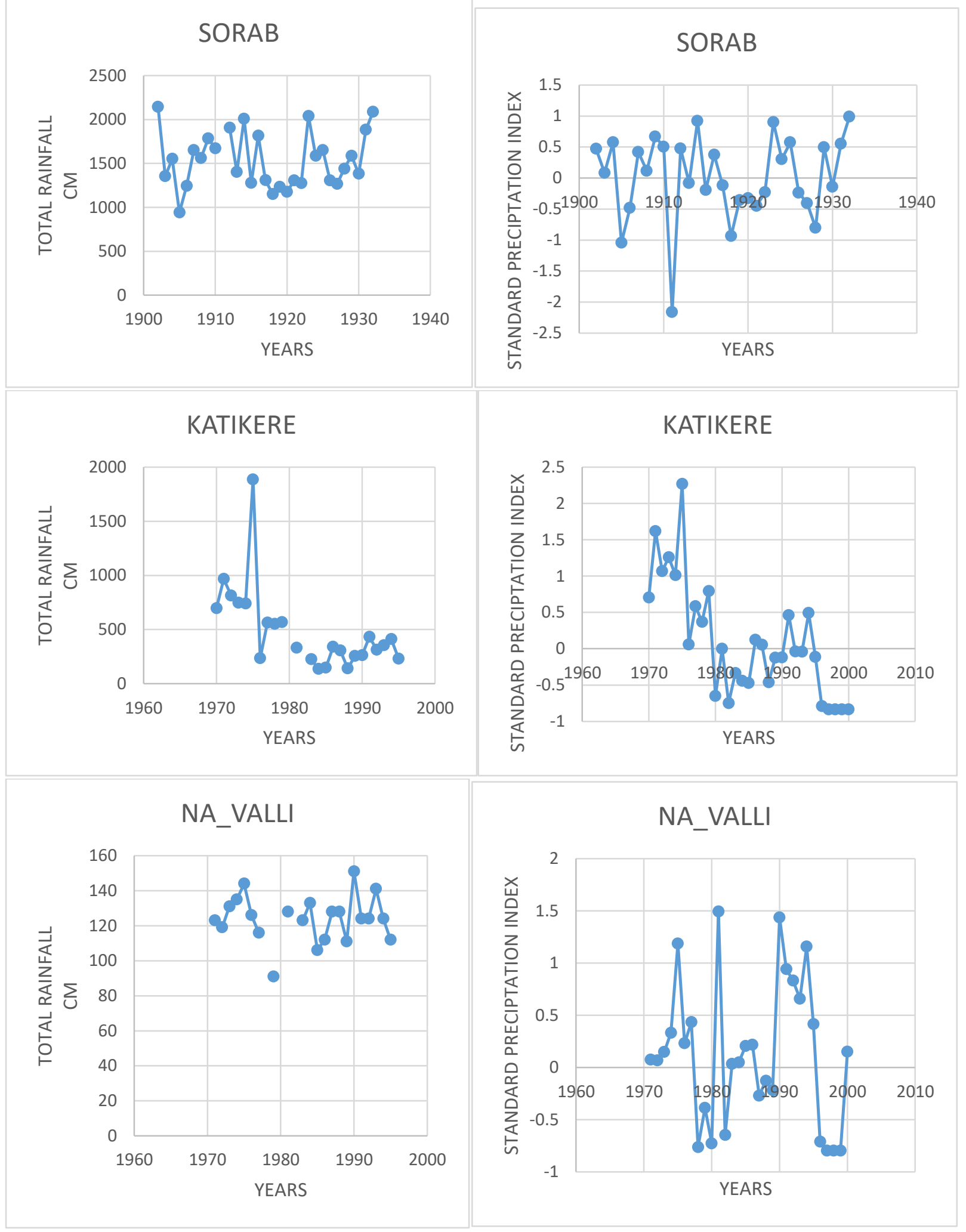

ISSN- 2350-0530(O), ISSN- 2394-3629(P)

IF: 4.321 (CosmosImpactFactor), 2.532 (I2OR)

InfoBase Index IBI Factor 3.86 
[Kothari et. al., Vol.5 (Iss.4: RASM), April, 2017]

ICV (Index Copernicus Value) 2015: 71.21

Recent Advances in Sustainable Materials

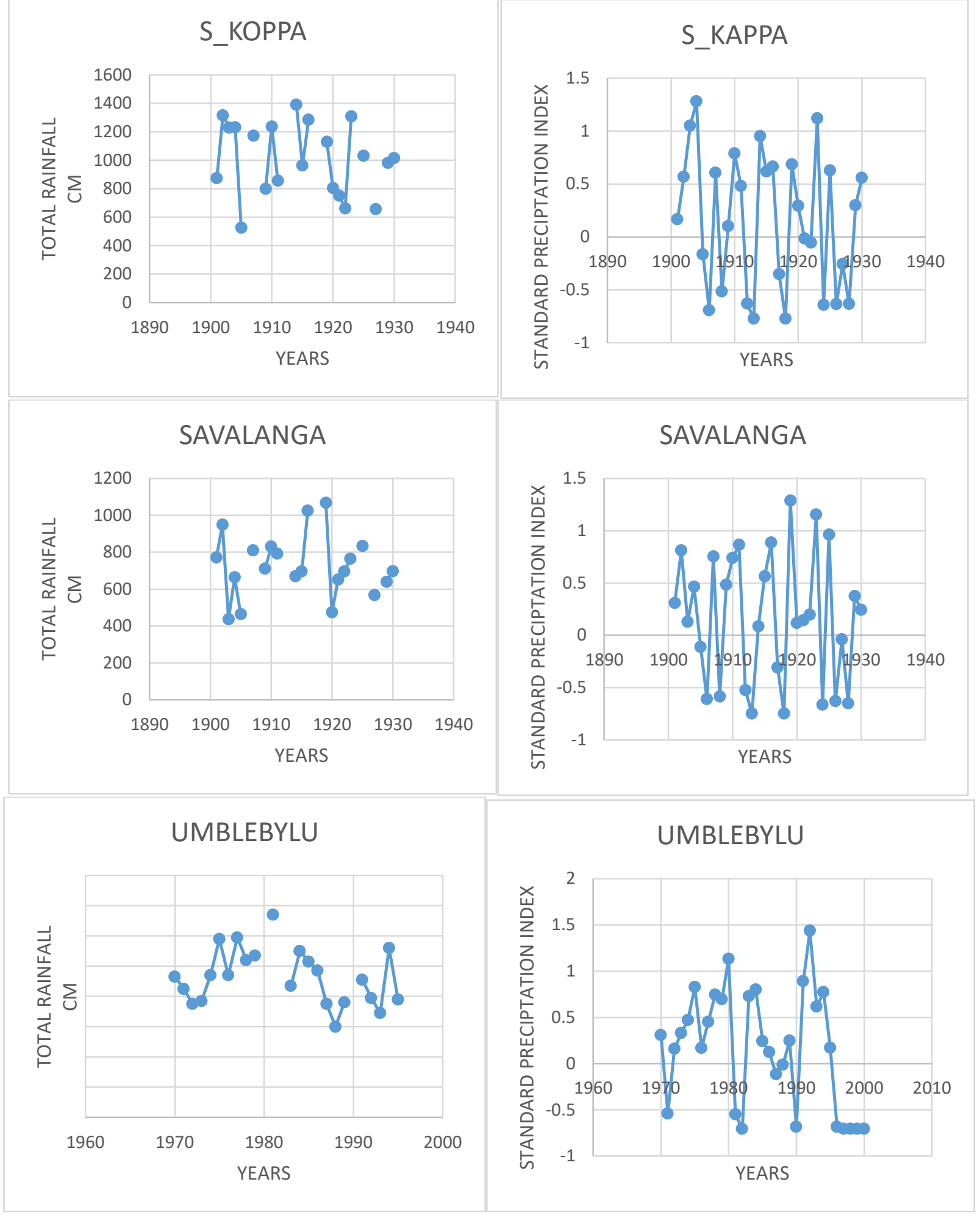

\section{Summary and Conclusion}

In this study the SPI values of different years are analyzed with actual rainfall and rainfall deviation from normal in the low rainfall and drought prone district. The object is to evaluate 
whether SPI can be used as a better indicator than conventionally adopted rainfall deviation based approach for drought intensity assessment.

Scatter plots of rainfall deviation vs. SPI indicated less sensitivity of SPI to low rainfall events. A very low or very high rainfall has not corresponded to a very low (-2.0 or less) or very high (-2.0 or more) SPI values. Thus, SPI values under estimated the dryness or wetness when the rainfall is very low or very high respectively.

From the data of Shivamogga district we got to know that Katikere station receives less amount of rainfall or precipitation, hence it is dry amongst all other stations whereas Na-Valli receives a good amount of rainfall every year. Therefore Katikere is more prone to drought.

\section{Acknowledgements}

Author would like to thank Sujan G. and Brahadeesh Kishore for their sincere support till the completion of paper. The cooperation offered by the officials of Directorate of Economics and Statistics, Government of Karnataka, M.S building Bangalore.

\section{References}

[1] WU Man-chi, a brief introduction to standardized precipitation index; www.hko.gov.hk>ele_spi_e retrieved on September 2013.

[2] M. Svoboba, M. Hayes AND D. Wood: World meterological precipitation organization, Standard precipitation user guide. 1090, 2012,3.

[3] Guttman, N.B., Accepting the standardized precipitation index user guide algorithm. J. Amer. Water resource: 1999, 35(2), 311-322

[4] Sangitha Mishra. S, Nagarajan. R: Drought accessment in the Tel Watershed, Indian Institute of Technology: 2011, 3

*Corresponding author.

E-mail address: kunalkothari2192@ gmail.com 